\title{
Percutaneous drainage and sclerotherapy as definitive treatment of renal lymphangiomatosis
}

\author{
Massimo Valerio, MD; Jean-Yves Meuwly, MD; ${ }^{\dagger}$ Cecile Tawadros, MD; ${ }^{*}$ Patrice Jichlinski, MD* \\ *Department of Urology, Centre Hospitalier Universitaire Vaudois, Lausanne, Switzerland; 'Department of Radiology, Centre Hospitalier Universitaire Vaudois, Lausanne, Switzerland
}

Cite as: Can Urol Assoc J 2012;6(1):e3-7. hitrp://dx.doi.org/10.5489/cuaj.11034

\section{Abstract}

We report the technique and outcome of percutaneous drainage and sclerotherapy as primary treatment of renal lymphangiomatosis. Between January and May 2009, two patients presenting with symptomatic renal lymphangiomatosis were treated in our department by a minimally invasive modality combining percutaneous drainage with repeated sclerotherapy. We retrospectively analysed recurrence, complications and patient satisfaction. In this limited case series, percutaneous drainage and repeated sclerotherapy proved to be safe and effective for treating renal lymphangiomatosis. This procedure provides a minimally invasive option for selected patients, potentially avoiding a surgical procedure and any risk of complications.

\section{Introduction}

Renal lymphangiomatosis $(\mathrm{RL})$ is a rare developmental malformation of the perirenal lymphatic system. It is due to the failure of the perirenal lymphatic tissue to form normal communications with the remainder of the lymphatic system. ${ }^{1}$ This leads to the dilation of lymphatic vessels and to the formation of unilocular or multilocular cystic masses in the perirenal area. Confusion exists in the literature. Some authors refer to $\mathrm{RL}$ as renal Iymphangiectasia. ${ }^{2}$ Thirty-six cases are described in the English literature. ${ }^{1,3-33}$ The differential diagnosis includes adult polycystic renal disease, von Hippel-Lindau disease, tuberose sclerosis, renal lymphoma with perirenal involvement and nephroblastomatosis. Computed tomography $(\mathrm{CT})$ and magnetic resonance imaging (MRI) play a key role in the diagnosis, as the findings in RL are typical. ${ }^{15,17,19}$ In the absence of symptoms, conservative management is considered the best treatment; open or preferentially laparoscopic surgery is recommended to avoid recurrence in symptomatic patients. ${ }^{1,7}$ Percutaneous drainage has been proposed as an alternative when surgery is contraindicated, but it is not a definitive solution as it is followed by recurrence. ${ }^{3}$

We report the technique and outcome of percutaneous drainage and sclerotherapy as primary definitive treatment in two consecutive patients presenting with symptomatic RL.

\section{Methods}

Two patients were referred to our department with right flank pain from January 2009 to May 2009. A CT and an MRI ruled out malignancy and suggested RL. Needle aspiration confirmed the diagnosis. Treatment options, such as open or laparoscopic approach, percutaneous drainage or conservative management, were discussed. Finally, drainage and povidone-iodine sclerosis were chosen based on the patients' previous lymphocele treatment on the basis of previous description of lymphocele treatment. ${ }^{34} \mathrm{~A}$ percutaneous drainage catheter (Flexima All Purpose Drain, Boston Scientific, Natick, MA) was placed using a trocar technique under ultrasound guidance. Intralesional aministration of $50 \mathrm{~mL}$ povidone-iodine $11 \mathrm{mg} / \mathrm{mL}$ (Betadine, Mundipharma, Hamilton, Bermuda) was injected twice daily through the catheter. Following the previously described technique of lymphocele sclerosis, the injected povidone-iodine was left in place in the cysts for 30 minutes. Afterwards, the drain was unclamped and the fluid flowed out freely. The drain was left in place until the daily volume of discharge was less than $30 \mathrm{~mL}$; then, it was removed.

Patients were closely followed up clinically and with renal function measurement and CT scan. Disease recurrence, complications and patient satisfaction were assessed at follow-up to quantify the outcome of this procedure. 


\section{Results}

\section{Case 1}

In January 2009, an 87-year-old man was referred to our hospital with right flank pain. The patient had significant medical morbidity: stenosis of the superior mesenteric artery, atrial fibrillation and severe coronary heart disease. For these reasons, he was anticoagulated and treated with antiplatelet drug. Physical examination and biochemical investigations were normal. A CT scan revealed moderate right renal pelviceal dilation and bilateral subcapsular hypodense lesions in the perinephric region within Gerota's fascia compatible with RL. An MRI confirmed the diagnosis (Fig. 1). Needle aspiration revealed a chylous content with a high content of lymphocytes and macrophages. Creatinine concentration in the fluid was similar to serum levels. A right ureteral pigtail catheter was introduced to relieve pain owing to renal dilation. Two months later, the patient developed heart failure due to compression of the great vessels by the right multicystic mass (Fig. 2).

Surgical treatment was not possible because of the patient's general condition, and so percutaneous drainage and sclerotherapy with a $10 \mathrm{~F}$ catheter was carried out for 21 days. The clinical result was excellent after the evacuation of $5 \mathrm{~L}$ of fluid. Pressure on the great vessels was completely relieved. No complication was noted during the hospital stay and at follow-up 2 months later; a CT-scan revealed no recurrence with normal renal function (Fig. 3). There was a complete relief of right flank pain and total patient satisfaction. The patient died 4 months after the drainage of acute myocardial infarction unrelated to the procedure.

\section{Case 2}

In May 2009, a 47-year-old man with no significant medical or family history presented with right flank pain. Physical and biochemical examination were normal. A CT scan showed right perirenal multilocular fluid-filled masses, with anteriormedial displacement of the right kidney (Fig. 4). The kidneys excreted contrast normally. An MRI revealed hyperintensive renal subcapsular lesions on T2-weighted compatible with RL. A high content of lymphocytes with normal creatinine value was found in the perinephric fluid obtained by needle aspiration. The patient underwent percutaneous drainage and sclerotherapy with an $8 \mathrm{~F}$ catheter. Daily povidoneiodine washing was performed for 18 days. The result was again excellent and no complication was recorded at each follow-up. Renal function remained normal. A CT-scan at 1, 3, 9 and 15 months showed no relapse of the lesions (Fig. 5). Right flank pain completely disappeared and the patient had no discomfort.

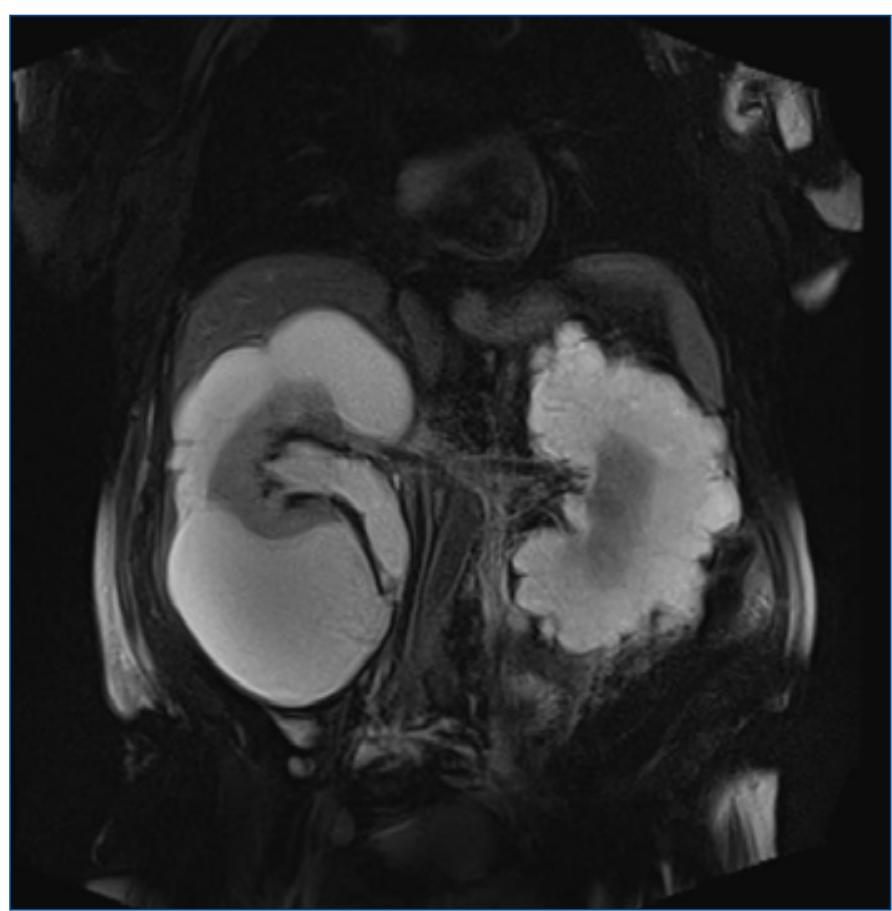

Fig. 1. Coronal T2-weighted magnetic resonance imaging shows bilateral renal multilocular hyperintense subcapsular lesions. These findings are typical of renal lymphangiomatosis.

\section{Discussion}

$\mathrm{RL}$ is a rare benign condition with no gender or age predilection. It can be either unilateral or bilateral. ${ }^{4,5}$ It is commonly sporadic, but hereditary cases have been described. ${ }^{6,31}$ Reported symptoms are non-specific, such as hematuria, abdominal pain and ipsilateral flank pain. Nevertheless, most patients remain asymptomatic and this anomaly is usu-

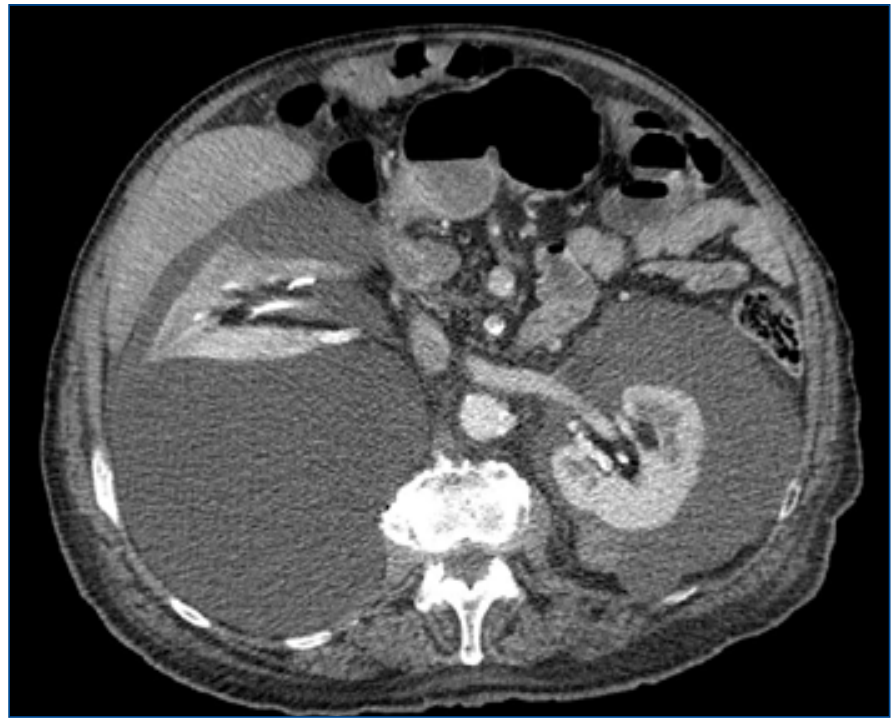

Fig. 2. Contrast enhanced computed tomography scan shows bilateral renal subcapsular hypodense lesions in the perinephric region within the Gerota's fascia compressing the right kidney and inferior vein cava. 


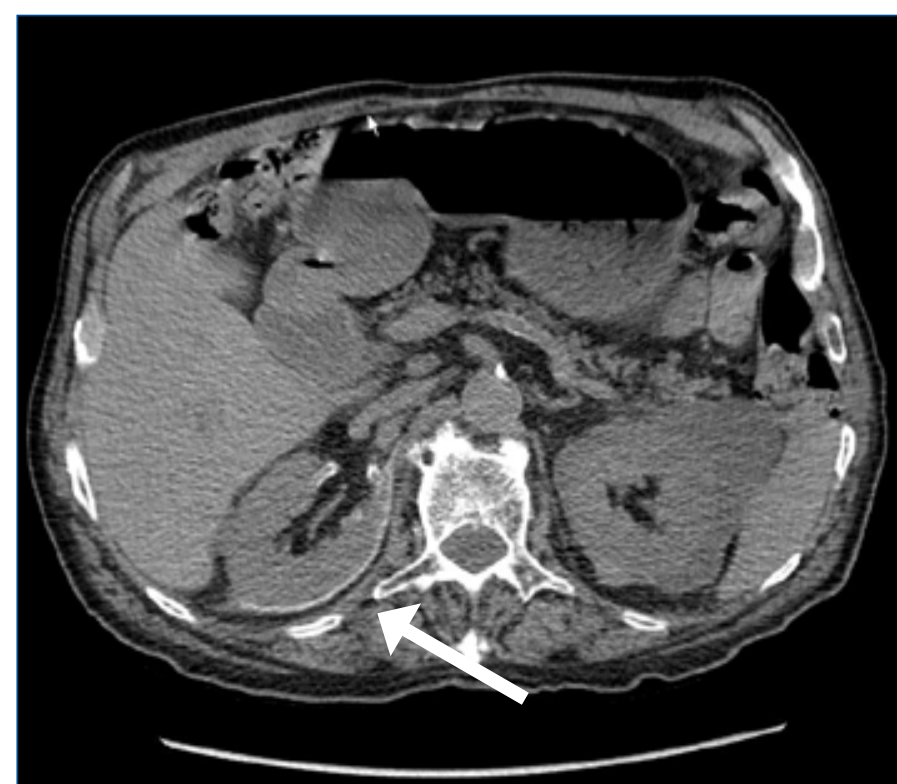

Fig. 3. Unenhanced computed tomography scan 2 months after the percutaneous drainage and sclerotherapy shows no recurrence. Observe the hyperdense rim around the right kidney related to povidone-iodine deposition on the wall of the cystic cavities (arrow). Contralateral fluid collections have also regressed. This confirms that there was a communication between the two perirenal masses.

ally detected incidentally on abdominal imaging performed for other reasons. Physical examination rarely reveals a palpable mass. Biochemical examination and renal function are usually normal. Complications, such as renal vein thrombosis, obstructive uropathy and renal hypertension, have been reported. ${ }^{4}$ Our first patient represents a rare association of heart failure in relation with RL.

A CT scan and MRI images are pathognomonic of the disease. On CT, perinephric lesions appear well-delineated with surrounding structures often displaced, but not invaded. ${ }^{15,17}$ Cyst attenuation lies in the range of water. An MRI typically shows the cysts as hypointense on T1-weighted images and hyperintense on T2 weighted images. ${ }^{19}$ Needle aspiration of the perirenal collections can confirm the diagnosis since chylous content with lymphocytes, protein and fat is typical of RL.,15

As of January 2011, there are 36 patients reported in literature (Table 1). Asymptomatic patients do not need treatment since the disease is benign and rarely leads to complications. However, depending on the patient's specific condition, symptomatic cases should be treated because the lesions rarely regress spontaneously. An open or laparoscopic approach with cyst marsupialisation or ablation of perirenal cysts is feasible. ${ }^{1}$ However, surgery can be hard to perform depending on the size and location of the cysts. Lesions in the renal hilum can be difficult to isolate and nephrectomy may have to be necessary. Lack of data in literature makes a comparison in functional outcome by dif-

\begin{tabular}{|c|c|c|}
\hline $\begin{array}{l}\text { Reference in } \\
\text { this article }\end{array}$ & $\begin{array}{c}\text { Year of } \\
\text { publication }\end{array}$ & Treatment \\
\hline 1 & 2007 & $\begin{array}{l}\text { Patient 1: Laparoscopic excision } \\
\text { Patient 2: Conservative }\end{array}$ \\
\hline 2 & 2001 & Percutaneous drainage \\
\hline 3 & 2009 & Conservative \\
\hline 4 & 2003 & Conservative \\
\hline 5 & 1988 & $\begin{array}{l}\text { Patient 1: Nephrectomy } \\
\text { Patient 2: Conservative }\end{array}$ \\
\hline 6 & 2007 & Conservative \\
\hline 7 & 2004 & Open excision \\
\hline 8 & 2011 & Conservative \\
\hline 9 & 1998 & Conservative \\
\hline 10 & 2010 & Percutaneous drainage \\
\hline 11 & 2009 & Nephrectomy \\
\hline 12 & 2008 & Conservative \\
\hline 13 & 2008 & Percutaneous drainage \\
\hline 14 & 2008 & Pateint 1 \& 2: Conservative \\
\hline 15 & 2007 & Conservative \\
\hline 16 & 2007 & Conservative \\
\hline 17 & 2006 & Conservative \\
\hline 18 & 2005 & Conservative \\
\hline 19 & 2004 & Nephrectomy \\
\hline 20 & 2002 & Conservative \\
\hline 21 & 2001 & Conservative \\
\hline 22 & 2000 & Conservative \\
\hline 23 & 1997 & Conservative \\
\hline 24 & 1997 & Nephrectomy \\
\hline 25 & 1995 & Percutaneous drainage \\
\hline 26 & 1992 & Nephrectomy \\
\hline 27 & 1987 & Conservative \\
\hline 28 & 1970 & Conservative \\
\hline 29 & 2010 & Conservative \\
\hline 30 & 2010 & Patient 1 \& 2: Conservative \\
\hline 31 & 2010 & Conservative \\
\hline 32 & 2006 & Conservative \\
\hline
\end{tabular}

ferent surgical techniques impossible. Symptomatic patients who were not eligible for surgery have thus far been treated by percutaneous drainage. ${ }^{3}$ This type of procedure is easy to perform, but only temporarily successful. It cannot be considered a therapeutic solution because it is inevitably followed by recurrence. Unfortunately, since the disease is rare, it can be mistaken for a malignant lesion and some patients are overtreated by nephrectomy. ${ }^{6,12,20,25,27}$

For our two patients, we preferred a minimally invasive modality combining percutaneous drainage with repeated long-acting sclerotherapy until total regression of the cysts was demonstrated. As in RL, the dilated lymphatic vessels are around the kidneys and within the renal sinus forming multiloculated cavities To favour a homogeneous sclerosing agent distribution and to avoid strictures on excretory system, 


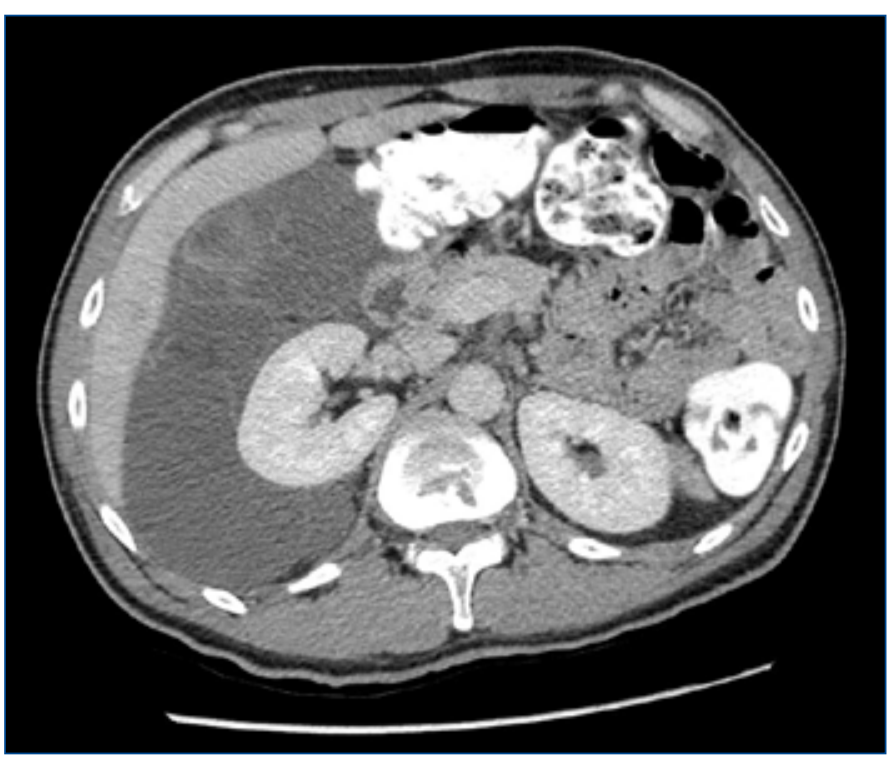

Fig. 4. Enhanced computed tomography scan reveals right perirenal hypodense fluid filled masses with antero-medial displacement of the right kidney.

we chose a long-acting agent (i.e., povidone-iodine) rather than alcohol. Povidone-iodine is also far cheaper than other agents (i.e., doxycycline).

Our patients supported the treatment well and had no procedural or postoperative complications. Follow-up CT showed no recurrence.

\section{Conclusion}

Our limited case series shows that this technique is safe and efficient. Larger series are needed to confirm these findings. Unfortunately, since the disease is rare and sometimes misunderstood, it is difficult to collect many cases. Nevertheless, we recommend this procedure as a first-line treatment in symptomatic patients presenting with $R \mathrm{~L}$ to reduce morbidity and avoid surgical complications.

Competing interests: None declared.

This paper has been peer-reviewed.

\section{References}

1. Wadhwa $P$, Kumar $A$, Sharma $S$, et al. Renal lymphangiomatosis: imaging and management of a rare renal anomaly. Int Urol Nephrol 2007;39:365-8. http://dx.doi.org/10.1007/s11255-006-9002-z

2. Ramseyer LI. Renal lymphangiectasia. Radiology 2001;219:442-4.

3. Ozmen $M$, Deren 0 , Akata $D$, et al. Renal lymphangiomatosis during pregnancy: management with percutaneous drainage. Eur Radiol 2001;11:37-40. http://dx.doi.org/10.1007/s003300000550

4. Bagheri MH, Zare Z, Sefiabakht S, et al. Bilateral renal lymphangiomatosis: sonographic findings. J Clin Ultrasound 2009;37:115-8. http://dx.doi.org/10.1002/icu.20488

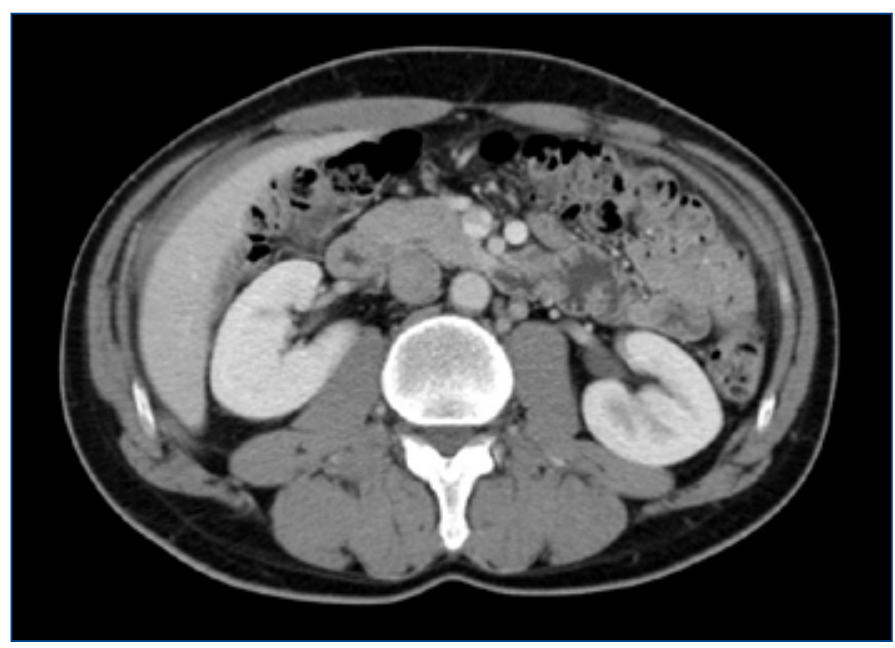

Fig. 5. Enhanced computed tomography scan 15 months after the treatment reveals no recurrence.

5. Mani NB, Sodhi KS, Singh P, et al. Renal lymphangiomatosis: a rare cause of bilateral nephromegaly. Australas Radiol 2003;47:184-7. http://dx.doi.org/10.1046/1.0004-8461.2003.01149.x

6. Meredith WT, Levine E, Ahlstrom NG, et al. Exacerbation of familial renal lymphangiomatosis during pregnancy. AJR Am J Roentgenol 1988;151:965-6.

7. Tornero Ruiz Jl, Ojados Castejon F, Nicolas Torralba J, e tal. [Bilateral renal lymphangiomatosis: conservative management]. Arch Esp Urol 2007;60:812-4.

8. Chiu IS, Wu CJ, Sun GH, et al. Obstructive uropathy associated with bilateral renal lymphangiomatosis. Nephrol Dial Transplant 2004;19:2923. http://dx.doi.org/10.1093/ndt/gfh291

9. Wani NA, Kosar T, Gojwari T, et al. Perinephric fluid collections due to renal lymphangiectasia. Am J Kidney Dis 2011;57:347-51. http://dx.doi.org/10.1053/i.ajkd.2010.06.028

10. Varela JR, Bargiela A, Requejo I, et al. Bilateral renal lymphangiomatosis: US and CT findings. Eur Radiol 1998;8:230-1. http://dx.doi.org/10.1007/s003300050368

11. Rastogi R, Rastogi UC, Sarikwal A, et al. Renal lymphangiectasia associated with chronic myeloid leukemia. Saudi J Kidney Dis Transpl 2010;21:724-7.

12. Chen Z, Qi L, Tang Z, et al. Renal lymphangiectasia. Scand I Urol Nephrol 2009;43:428-30. http:// dx.doi.org/10.3109/00365590902930857

13. Sanchez F, Prieto IC, Koral K, et al. Childhood renal lymphangiectasia. Int Braz I Urol 2008;34:772-3. http://dx.doi.org/10.1590/S1677-55382008000600013

14. Rastogi R, Rastogi V. Computed tomographic scan in the diagnosis of bilateral renal lymphangiectasia. Saudi J Kidney Dis Transpl 2008;19:976-9.

15. Upreti L, Dev A, Kumar Puri S. Imaging in renal lymphangiectasia: report of two cases and review of literature. Clin Radiol 2008;63:1057-62. http://dx.doi.org/10.1016/i.crad.2007.12.013

16. Ueda $S$, Yanagida $H$, Sugimoto $K$, et al. Chronic renal insufficiency in a boy with cystic renal lymphangiectasia: morphological findings and long-term follow-up. Clin Nephrol 2007:68:416-21.

17. Ashraf K, Raza SS, Ashraf 0, et al. Renal lymphangiectasia. Br J Radiol 2007;80:e1 17-8. http://dx.doi. org/10.1259/bir/16931054

18. Pianezza ML, Mokhtassi A, Wu L, et al. Case report: renal lymphangiectasia. Can J Urol 2006;13:3204-7.

19. Kocaoglu M, Bulakbasi N, llica T, et al. MRI findings of renal lymphangiectasia. J Magn Reson Imaging 2005;22:681-3. http://dx.doi.org/10.1002/imri.20437

20. Ratti M, Ammar L, Zennaro F, et al. Renal lymphangiectasia. Pediatr Radiol 2004;34:669-70. http:// dx.doi.org/10.1007/s00247-004-1157-0

21. Llorente JG, Garcia AD, Sacristan JS, et al. Renal lymphangiectasia: radiologic diagnosis and evolution. Abdom Imaging 2002;27:637-9. http://dx.doi.org/10.1007/s00261-001-0147-z

22. Sombolos Kl, Papachillea Al, Natse TM, et al. End-stage renal disease in a patient with congenital lymphangiectasia and lymphedema. Pediatr Nephrol 2001;16:151-3. http://dx.doi.org/10.1007/ s004670000526

23. Cadnapaphornchai MA, Ford DM, Tyson RW, et al. Cystic renal lymphangiectasia presenting as renal insufficiency in childhood. Pediatr Nephrol 2000;15:129-31. http://dx.doi.org/10.1007/s004670000413

24. Riehl J, Schmitt H, Schafer L, et al. Retroperitoneal lymphangiectasia associated with bilateral renal vein thrombosis. Nephrol Dial Transplant 1997;12:1701-3. http://dx.doi.org/10.1093/ndt/12.8.1701 
25. Simonton SC, Saltzman DA, Brennom W, et al. Cystic renal lymphangiectasia: a distinctive clinicopathologic entity in the pediatric age group. Pediatr Pathol Lab Med 1997;17:293-301. http://dx.doi. org/10.1080/107710497174949

26. Merguerian PA, Sargent SK, Dunn JL. Unilateral lymphangiectasis of the kidney: an unusual cause of renal enlargement in an infant. J Urol 1995;153:447-9. http://dx.doi.org/10.1097/00005392199502000-00053

27. Murray KK, McLellan GL. Renal peripelvic lymphangiectasia: appearance at CT. Radiology 1991;180:455-6.

28. Kutcher R, Mahadevia P, Nussbaum MK, et al. Renal peripelvic multicystic lymphangiectasia. Urology 1987;30:177-9. http://dx.doi.org/10.1016/0090-4295(87)90191-9

29. Lindsey JR. Lymphangiectasia simulating polycystic disease. J Urol 1970;104:658-62.

30. Hakeem A, Gojwari TA, Reyaz $S$, et al. Computed tomography findings in bilateral perinephric lymphangiomatosis. Urol Ann 2010;2:26-8. http://dx.doi.org/10.4103/0974-7796.62922

31. Antonopoulos R, Charalampopoulos $G$, Constantinidis $F$, et al. Familial renal retroperitoneal lymphangiomatosis: personal experience and review of literature. JBR-BTR 2010;93:258-61.
32. Beveridge N, Allen L, Rogers K. Lymphoscintigraphy in the diagnosis of lymphangiomatosis. Clin Nucl Med 2010;35:579-82. httr://dx.doi.org/10.1097/RLU.0b013e3181e4dc3c

33. Sarikaya B, Akturk $Y$, Bekar $U$, et al. Bilateral renal lymphangiomatosis mimicking hydronephrosis: multidetector CT urographic findings. Abdom Imaging 2006;31:732-4. http://dx.doi.org/10.1007/ s00261-005-8014-y

34. Gilliland JD, Spies JB, Brown SB, et al. Lymphoceles: percutaneous treatment with povidone-iodine sclerosis. Radiology 1989;171:227-9.

Correspondence: Dr. Massimo Valerio, Department of Urology, Centre Hospitalier Universitaire Vaudois, 1011, Lausanne, Switzerland; fax: + 41213142 985; massimo.valerio@chuv.ch 